Over the years, Hong Kong has also developed close research collaborations with major academic centres in mainland China, particularly in the area of psychosis, suicide and epidemiology.

\section{Links with mainland China}

Since the hand-over of Hong Kong in 1997, links between Hong Kong and mainland Chinese psychiatrists have gradually developed. Joint scientific conferences, exchanges and clinical attachments for psychiatrists are regularly organised between the two sides. In the past 3 years, a tripartite training scheme jointly organised by the Chinese University of Hong Kong, the University of Melbourne and local psychiatric institutes has facilitated the training of a large number of mainland psychiatrists and mental health workers. This has centred on imparting the knowledge, skills and practical information to implement community psychiatric care for patients with severe mental illness.

\section{Future directions and conclusion}

The mental health service in Hong Kong is undergoing tremendous change. With a firm foundation in education, training, legislation and research in psychiatry, despite meagre public spending on mental healthcare, Hong Kong has developed a highly efficient mental health service that addresses the basic mental health needs of its citizens with a hospital-based secondary and tertiary care model. However, this system is becoming unsustainable, because of the increasing pressure of demand. In the last 10 years or so, a gradual reform of the mental health service has begun. It is hoped that the service will be transformed from a system characterised by the efficient management of patients to a system that delivers personalised care to patients, informed by the cutting edge of psychiatric research.

\section{References}

Central Intelligence Agency (2010) The World Factbook: Hong Kong Available at https://www.cia.gov/library/publications/the-worldfactbook/geos/hk.html (last accessed April 2010).

Cheung, H. K. (2000) The new mental health ordinance 1996 to 1997 - a reference guide for physicians and mental health workers. Hong Kong Journal of Psychiatry, 10, 3-13.

Hong Kong College of Psychiatrists (2007) Submission of the Hong Kong College of Psychiatrists to the Food and Health Bureau on Mental Health Policy in Hong Kong. HKCP.

Hong Kong College of Psychiatrists (2008) Education, Training and Examination for Fellowship. HKCP.

Lo, W. H. (1988) Development of legislation for the mentally ill in Hong Kong. Journal of the Hong Kong Psychiatric Association, 8, 6-9.

World Health Organization (2005) Mental Health Atlas. WHO.

\title{
Mental health profile of Greece
}

\section{George Christodoulou MD FRCPsych, ${ }^{1}$ Dimitris Ploumpidis MD, ${ }^{2}$ Nikos Christodoulou MBBS MSc MRCPsych ${ }^{3}$ and Dimitris Anagnostopoulos MD ${ }^{4}$}

\footnotetext{
${ }^{1}$ Emeritus Professor of Psychiatry, Honorary President, Hellenic Psychiatric Association, Greece, email gchristodoulou@ath.forthnet.gr; ${ }^{2}$ Associate Professor of Psychiatry, First Psychiatric Department of Athens University; ${ }^{3}$ University College London Hospital, London, UK; ${ }^{4}$ Assistant Professor of Child and Adolescent Psychiatry, First Psychiatric Department of Athens University, Greece
}

\footnotetext{
ince the mid-1980s, a profound reform in the organisation of mental health provision has been taking place in Greece (Madianos \& Christodoulou, 2007; Christodoulou, 2009). The aim has been to modernise the outdated system of care (Christodoulou, 1970), which was based on inpatient asylum-like treatment, the beginning of which can be roughly dated to the second half of the 19th century (Christodoulou et al, 2010).

Two major programmes of financial and technical assistance from the European Union, Regulation 815/1984 (1984-94) and Psychargos I and II (1999-2007), greatly contributed to the implementation of the reform. Their main targets were the following:

the provision of community psychiatric services in sectors ('sectorisation')

a progressive reduction in the number of traditional hospitals, in parallel with the creation of a network of housing units

the creation of psychiatric units in general hospitals
}

the creation of mobile units in rural areas and the islands

$O$ the establishment of a network of units for psychosocial rehabilitation

o the establishment of pilot units for psychogeriatric patients and people with autism.

\section{Mental health policy and legislation}

Law 1397 of 1983 on the National Health System provided the legal framework for the psychiatric reform.

Law 2071 of 1992 aimed to modernise the conditions of care in Greece, especially regarding involuntary hospitalisation, and introduced the principle of 'sectorisation' (the establishment of sectors of 250000-280000 inhabitants) in the provision of services.

Law 2444 of 1996, especially articles 1666-88, offers broad legal guarantees to persons under court protection orders. 
Law 2716 of 1999 defined the principles of mental health practice in Greece (article 1) and identified the 'units of mental health' (articles 4-12). Sectorisation was again a key principle. This law also introduced the concept of 'social cooperative units' (Kot.इ.П.E.), which give people with mental health problems and other disabilities the opportunity to engage in work.

\section{Mental health service delivery}

Mental health services are provided by the public sector, by non-profit units and by the private sector.

Sectorisation has yet not been systematically organised. There are also deficiencies in primary care and in follow-up, creating increased demand for beds (because the filters that would prevent admission to hospital do not work well).

The dysfunctional aspects of the system are manifest in:

$O$ the high rates of involuntary hospital admissions (over $50 \%$ of admissions in public psychiatric hospitals and $35-40 \%$ of those to psychiatric units in general hospitals in Athens, although in other cities the rates are lower - see Tables 1 and 2)

O the frequent use of 'auxiliary beds' in public units, especially in the psychiatric units of general hospitals in the Athens area.

\section{Sectorisation - networking of psychiatric services}

There are 13 sectors for the Athens area and three for the area of Thessaloniki. Each sector has in principle the responsibility

Table 1 Public psychiatric hospitals in Greece

\begin{tabular}{|c|c|c|c|}
\hline & $\begin{array}{l}\text { Number } \\
\text { of beds } \\
\text { for acute } \\
\text { patients }^{a}\end{array}$ & $\begin{array}{l}\text { Number of } \\
\text { admissions } \\
\text { per yearb }\end{array}$ & $\begin{array}{l}\text { Proportion of } \\
\text { admissions that } \\
\text { are involuntary }\end{array}$ \\
\hline $\begin{array}{l}\text { Psychiatric Hospital of } \\
\text { Athens }\end{array}$ & 250 & 2800 & $52-55 \%$ \\
\hline $\begin{array}{l}\text { Dromokaition } \\
\text { Psychiatric Hospital } \\
\text { (Athens) }\end{array}$ & 180 & 1560 & $50-52 \%$ \\
\hline $\begin{array}{l}\text { Psychiatric Hospital of } \\
\text { Thessaloniki }\end{array}$ & 120 & 3300 & $26-29 \%$ \\
\hline $\begin{array}{l}\text { Psychiatric Hospital of } \\
\text { Tripolis }\end{array}$ & 100 & 1015 & $59-63 \%$ \\
\hline $\begin{array}{l}\text { Psychiatric Hospital of } \\
\text { Leros }\end{array}$ & $20-22$ & 190 & $31-32 \%$ \\
\hline
\end{tabular}

aThere are additional beds occupied by chronic patients and also in housing units outside the hospitals.

${ }^{\mathrm{b}}$ The Psychiatry Department of Athens University (Eginition hospital) additionally admits approximately 500 voluntary patients per year.

Table 2 Psychiatric units in general hospitals ${ }^{a}$

\begin{tabular}{lrrrr|} 
& $\begin{array}{l}\text { Number } \\
\text { of units }\end{array}$ & $\begin{array}{l}\text { Total } \\
\text { number } \\
\text { of beds }\end{array}$ & $\begin{array}{l}\text { Number of } \\
\text { admissions } \\
\text { per year } \\
\text { (approximate) }\end{array}$ & $\begin{array}{l}\text { Proportion of } \\
\text { admissions that } \\
\text { are involuntary }\end{array}$ \\
\hline $\begin{array}{l}\text { Athens } \\
\text { Other cities }\end{array}$ & 8 & $150-160$ & 2700 & $35-40 \%$ \\
& 12 & 200 & 5200 & $22-23 \%$
\end{tabular}

aThey generally have 20 beds, but some of these are not always in use, mainly due to insufficient nursing staff.

${ }^{\text {b}}$ This figure is approximate and we have not included six units that do not admit involuntary patients. for out-patient and in-patient care within the sector, but few of them are sufficiently developed to satisfy this requirement. Each sector is regulated by a sectoral committee of mental health (T.E.Y.Y.), a body whose responsibility it is to coordinate the out-patient and in-patient units, which usually belong to a variety of mental health facilities run by various organisations. It is felt that in order to fulfil their mission, the sectors must be adequately funded and be entrusted with sufficient authority for decision making.

\section{Hospital admissions}

Data from 2006 and 2007, collected by a committee established by the Hellenic Psychiatric Association (Ploumpidis et al, 2008), indicate the following:

\section{Public psychiatric hospitals}

Admissions to the nine public psychiatric hospitals have steadily diminished since the late 1970s (Madianos \& Christodoulou, 2007). Four of them (the psychiatric hospitals of Petra-Olympus, Corfu, Crete and the child psychiatric hospital of Attiki) have practically closed down, although they still provide administrative services to the hostels, out-patient units and psychosocial rehabilitation centres in their areas.

The five fully functioning public psychiatric hospitals maintain many hostels, rehabilitation units and out-patient units. There is a high rate of involuntary admission to them.

\section{Psychiatric units in general hospitals}

Fifty-four hospitals have out-patient facilities and liaison psychiatry, but only 20 of them also have in-patient units. Six more units in general hospitals will start admitting patients as soon as they resolve their staff shortages (mainly nursing).

The majority of these units have been created in the last 25 years. Their contribution to the implementation of psychiatric reform has been substantial. Many of them house university departments of psychiatry.

In the Athens area, many of these psychiatric units are overcrowded and 'auxiliary beds' are used to accommodate the patients. In the rest of the country, conditions are better.

\section{Out-patient care}

The largest social security organisation (I.K.A.) offers primary care through its out-patient services. Practically all in-patient psychiatric facilities also offer out-patient services.

There are nine mental health centres in Athens, three in the Thessaloniki area and 22 in the rest of the country (a total of 34). These facilities offer the possibility of combining primary mental healthcare, psychotherapy and day hospital services.

Primary psychiatric care is carried out by general practitioners, healthcare centres and psychiatrists and physicians in private practice, especially in rural areas.

Sectorisation is certainly a prerequisite for the meaningful organisation of services, but in spite of efforts this has not been achieved to the desired extent.

\section{Housing units}

The programme of deinstitutionalisation has been based on the creation of a network of housing units. In 2005 there were 377 housing units, 269 state-owned and 108 run by non-governmental organisations (NGOs). These units served 2695 users and employed 3061 professional staff. Recent budgetary problems have affected the operation of these units, especially those run by NGOs. 


\section{Rehabilitation units}

In the 1990s, psychosocial rehabilitation developed remarkably in Greece. Social and pre-vocational rehabilitation programmes are still active but vocational rehabilitation has regressed, following increasing difficulties in the labour market. The social cooperative units mentioned above have yet to be fully developed.

\section{Private facilities}

In the Athens area there are 12 private psychiatric hospitals, with a total of approximately 1700 beds. They have a high proportion of chronic patients and bed occupancy approaching 100\%. In Macedonia (northern Greece) there are nine units with a total of 1430 beds and in Thessaly (central Greece) there are nine units with a total of 1175 beds.

\section{Psychiatric training}

Undergraduate psychiatric training is carried out in the six medical schools of the country.

There are several available postgraduate degree programmes related to mental health. Postgraduate training is carried out in university and state hospital settings. Specialty training in psychiatry lasts for 5 years and consists of 6 months of training in general medicine, 12 months in neurology and 42 months in psychiatry. There are more than 2000 psychiatrists in Greece.

Child psychiatry was established as a specialty in 1980. Training lasts 4 years 6 months (18 months in adult psychiatry, 6 months in neurology and 30 months in child psychiatry). More than 300 child psychiatrists practise in Greece.

For both specialties, the certificate of specialist training is provided after an oral (and sometimes a written) examination by a committee of psychiatrists appointed by the Ministry of Health. The Hellenic Psychiatric Association has requested greater involvement of the Association in training and examinations as well as harmonisation with the recommendations of the European Board of Psychiatry of the Union Européenne des médecins spécialistes (EUEMS; European Union of Medical Specialists).

\section{Psychiatric subspecialties and allied professions}

Psychiatrists regularly collaborate with other mental health professionals (especially psychologists, psychiatric nurses and social workers).

\section{Child and adolescent psychiatry}

Law 2716 of 1999 introduced sectorisation of child and adolescent psychiatric services, which was implemented only in the Athens and Thessaloniki areas.

One of the main targets of psychiatric reform in child psychiatry was the closure of the Child Psychiatric Hospital of Attiki, which had operated since 1960, mainly with children with severe intellectual difficulties. Reform was achieved with the creation of modern community services.

There are nine child and adolescent mental health centres - eight in the Athens area and one in the Thessaloniki area. Also, three units (of 10 beds each) are hosted in paediatric hospitals (one in Athens and two in the Thessaloniki area). There has been an adolescent psychiatry unit in Athens since 1985 and one in Thessaloniki since 2009

Six psychiatric hospitals and 20 paediatric hospitals run child guidance clinics. In addition, eight child guidance clinics are run by the Hellenic Centre for Mental Health and Research and two are run by other non-profit organisations.

\section{Psychiatric nursing and psychotherapy}

There are too few nursing staff in the public sector, mainly due to budgetary restrictions. There is a postgraduate, 1-year national training programme for psychiatric nursing, which leads to the Certificate of Psychiatric Nursing.

Training mainly in psychoanalytic, behavioural and cognitive psychotherapies is available at private and university units, affiliated to international organisations.

Budgetary deficits are evident in relation to psychiatric nursing and psychotherapy.

\section{Research}

Research is carried out mainly in clinical psychiatry, biological psychiatry, social psychiatry, community-based psychiatry, psychosocial rehabilitation and psychotherapies. Research is also carried out by non-medical professionals, mainly psychologists.

\section{Human rights}

There has been progress with respect to the human rights of service users. Ethics committees in research programmes are obligatory. Law 2716 of 1999 introduced the Special Committee for the Control and Protection of the Rights of Persons with Psychological Disorders. Its annual reports of 2007, 2008 and 2009 pointed out omissions in several units.

A wide-ranging anti-stigma programme has been implemented since 2000 (Economou et al, 2005; Ploumpidis et al, 2009) and mental health promotion programmes are being implemented by a number of agencies, notably the Hellenic Psychiatric Association and the Psychiatry Department of Athens University.

\section{International initiatives}

The Hellenic Psychiatric Association has representation on many international organisations (e.g. the WPA, EPA, ICPM, PAEEB, WFMH, RCPsych) and is active in initiatives that aim to increase scientific collaboration with psychiatric societies in Eastern Europe, the Balkans (see http://www.paeeb.com) and the Middle East. The Association has mediated locally in Israel, Lebanon and Palestine for the production of anti-war statements, in collaboration with the relevant task forces of the World Psychiatric Association, and has undertaken mental health promotion initiatives in Serbia, Albania, Iraq and Cyprus. Recently it has begun collaborating with the World Health Organization on an 'advanced psychiatry' course in Palestine. 


\section{Conclusion}

The Greek mental healthcare system is now largely based on prevention, community care and limited in-hospital care (Thornicroft et al, 2008). However, there are serious problems, stemming mainly from funding difficulties and the resulting staff shortages.

\section{References}

Christodoulou, G. N. (1970) Psychiatry in Greece. International Journal of Social Psychiatry, 16, 314-316.

Christodoulou, G. N. (2009) Psychiatric reform revisited. World Psychiatry, 8, 121-122.
Christodoulou, G. N., Ploumpidis, D. N. \& Karavatos, A. (eds) (2010) Anthology of Greek Psychiatric Texts. Beta.

Economou, M., Gramandani, C., Richardson, C., et al (2005) Public attitudes towards people with schizophrenia in Greece. World Psychiatry, 4 (suppl. 1), 40-44.

Madianos, M. G. \& Christodoulou, G. N. (2007) Reform of the mental healthcare system in Greece. International Psychiatry, 4, 6-19.

Ploumpidis, D., Garani-Papadatou, T. \& Economou, M. (2008) Deinstitutionalisation in Greece: ethical problems. Psychiatriki, 19, 320-329.

Ploumpidis, N. D. (coordinator), Karavatos, A., Ploumpidis, N. D., et al (2009) Report of the Committee of Psychiatric Reform, Years 2006-2008. Hellenic Psychiatric Association. Available at http://www. psych.gr (in Greek).

Thornicroft, G., Tansella, M. \& Law, A. (2008) Steps, challenges and mistakes to avoid in the implementation of community mental health care. World Psychiatry, 2, 87-92.

COUNTRY PROFILE

\section{Mental health profile of Ghana}

\section{J. B. Asare MD FRCPsych FWACP FGCP\&S}

Retired Chief Psychiatrist, Ghana, email jbasarek@yahoo.co.uk hana is a West African state that attained independence from Great Britain in 1957 and became a republican state in 1960 . Its population is about 22 million (2004 estimate), distributed in ten regions. The World Health Organization (WHO) has estimated that 650000 of the population are suffering from severe mental disorder and 2166000 are suffering from moderate to mild mental disorder (see http://www.who.int/mental_health/policy/ country/ghana/en).

Mental health activities started with the enactment of the Lunatic Asylum Ordinance in 1888 by the colonial government of the Gold Coast (as Ghana was then known). The ordinance allowed law-enforcement agencies to arrest people suspected of having a mental illness (at least those who were roaming about in towns, villages or the bush) to be confined in an abandoned prison in Accra. That facility soon became overcrowded, necessitating the provision of the Lunatic Asylum in 1906. The Asylum eventually became Accra Psychiatric Hospital (Ewusi-Mensah, 2001). Two other purpose-built psychiatric hospitals, the Ankaful Psychiatric Hospital and Pantang Hospital, were opened in 1965 and 1975, respectively. The first President of Ghana had a vision of making Pantang a pan-African mental health village for research into neuropsychiatric conditions but his vision was not realised before his overthrow in 1966.

\section{Mental health policy and legislation}

Ghana's mental health policy was formulated in 1994, and revised in 2000 and 2004 . The policy objective is to provide facilities at the tertiary, regional, district and sub-district levels for the management of psychiatric cases. In pursuit of this, each regional hospital is meant to have a psychiatric wing with 10-20 beds.

The policy of the Ministry of Health is to shift the focus of mental health treatment from institutionalised care to community care, integrated into general healthcare (according to the draft Mental Health Bill 2010). Decentralisation of mental health services has been pursued with the aim of increasing access, which has involved training more psychiatric nurses, medical officers in the district hospitals and non-mental health personnel. Ten general duty doctors were trained to head the regional wings, but only three of them could be engaged in the regions, while the others have augmented the staff at the specialist hospitals. The other policies set out in the Bill cover the formation of a technical coordinating committee, training, the rehabilitation of people who are mentally ill and periodic review of conditions of service for mental health personnel.

After the promulgation of the Lunatic Asylum Ordinance of 1888, the National Redemption Council Decree (NRCD 30) of 1972 followed. This was an institution-based law that did not address human rights adequately but was an improvement on the previous law. Unsuccessful attempts were made in 1992, 1996 and 2000 to revise the law. Since 2004, a more comprehensive Bill has been prepared with the technical assistance of the WHO and will soon be put before Parliament. The new Bill adopts an approach based on human rights, in accordance with international agreements (such as the United Nations Charter) on the health needs of people with mental disorders (WHO, 2005). The Bill applies to the private as well as the public sector. It addresses community care, which involves orthodox, traditional and spiritual practices, and the monitoring of activities in order to bring dignity to people suffering from mental illness. The Bill also ensures that standards of care and patients' rights are adhered to in order to prevent physical and sexual abuse. 